\title{
Histological Difference between Retrograde Corpora Lutea of Pregnancy and Those of Estrus in Sika Deer, Cervus nippon
}

\author{
Isao KITA, Seiki TAKATSUKI ${ }^{1)}$, and Tosiro TIBA \\ Department of Theriogenology, Faculty of Agriculture, Gifu University, 1-1 Yanagido, Gifu 501-11 and ${ }^{1)}$ Biological Institute, Faculty of \\ Science, Tohoku University, Aoba-ku, Sendai 980, Japan
}

(Received 6 July 1993/Accepted 15 November 1993)

\begin{abstract}
Histological characteristics of retrograde corpora lutea (RCL) were examined for 105 pairs of ovaries of adult female sika deer, Cervus nippon. Animals were captured in various seasons at Mt. Goyo, Iwate Prefecture, the northern part of Japan. No histological differences were recognizable between RCL of pregnancy and retrograde accessory corpora lutea (RACL), so far as examined by means of hematoxylin-eosin and Weigert's resorcinfuchsin staining. They were both irregularly shaped and had well developed arteries in their thick capsules and a number of small arteries in the parenchyma. These arteries showed the proliferation of elastic fibers showing elastosis in older RCL. The total number of these retrograded bodies per female increased with age, suggesting that both the retrograded bodies would retain in the ovaries over 7 years. RCL of estrus were small hyaline bodies scattered with some degenerated luteal cells in the hyaline matrix. They were distinguishable from those of pregnancy since the capsule and parenchyma in those of estrus were poorer in blood vessels. RCL of estrus appeared in October and November but were rarely seen in February and March, suggesting that they will disappear within three months after ovulation.--KEY wORDS: accessory corpus luteum, breeding history, past gestation, retrograde corpus luteum, sika deer.
\end{abstract}

J. Vet. Med. Sci. 56(2): 309-314, 1994

Since RCL are positive evidence for the past ovulation or gestation, the data on their presence/absence and number in the ovaries are very helpful to know reproductive performances of breeding in the wild animals. That is, RCL of pregnancy provide an index of number of experienced deliveries for monotocous animals such as the sperm whale [1] and the Japanese serow [12], and are used as indices of litter size for polytocous ones such as the Hokkaido brown bear (Tsubota, personal communication). RCL of estrus, on the other hand, can be used as an evidence of failure of conception in spite of ovulation occurred (e.g., Japanese serow [9]). In order to assess the actual breeding conditions based on the RCL data, it is prerequisite to distinguish the two different RCL's and to elucidate their respective lifetimes during which they are retained in the ovaries. For the white-tailed deer and black-tailed deer, the histological difference of these RCL's and their lifetimes have already been established, and examinations of ovaries have been carried out in an attempt to estimate their actual breeding conditions $[3,5]$.

For the sika deer, however, the corresponding examination method of ovaries has not yet been established, although Yamauchi et al. [16] have briefly reported the existence of both the RCL's in the regressing process. The sika deer, one of the seasonal polyestrous, animals whose mating season is from September to November, delivers single fawn after the gestation period of about 220 days [2]. This animal, though monotocous, often has two corpora lutea, with the smaller one traditionally referred to as accessory corpora lutea (ACL) $[8,13]$. Because either origin or function of these small bodies is not clear, difficulties are met with analyzing ovarian examination data for this species.

In the present study, the authors detected, other than
RCL of pregnancy, small bodies which seemed to be RCL of estrus in the ovaries. In this paper, the findings and the differential points of the two RCL's are described below.

MATERIALS AND METHODS

One hundred and five sexually matured female sika deer $(2,11,85,9$ and 4 females during October, November, February-March, June-July and September, respectively) were examined for pairs of ovaries. The females were captured in 1990-1992 at Mt. Goyo, Iwate Prefecture, by a "pest control program". Of these animals, the age was estimated for 46 individuals by counting cement annual rings of the first incisors. The ovaries were sliced at $2 \mathrm{~mm}$ intervals, were observed macroscopically and were examined histologically after staining with hematoxylin-eosin and Weigert's resorcinfuchsin.

RESULTS

Corpora lutea of pregnancy and $A C L$ : Corpora lutea of pregnancy were found to keep their dimensions until the latest stage of pregnancy, with only minimal degeneration noted in luteal cells (Fig. 1). ACL were present in the ovaries of $38 / 45(84 \%)$ pregnant females captured during the mid pregnancy period (February $\sim$ March), and identified as such from their apparently smaller size than corpora lutea of pregnancy, while at the latest stage of pregnancy, no more histological differences were noted between the two. This is because the cellular degeneration remained minimal for ACL (Fig. 2). In the ovaries of females supposed to have had delivered shortly before from macroscopic findings of their uterus, both the 

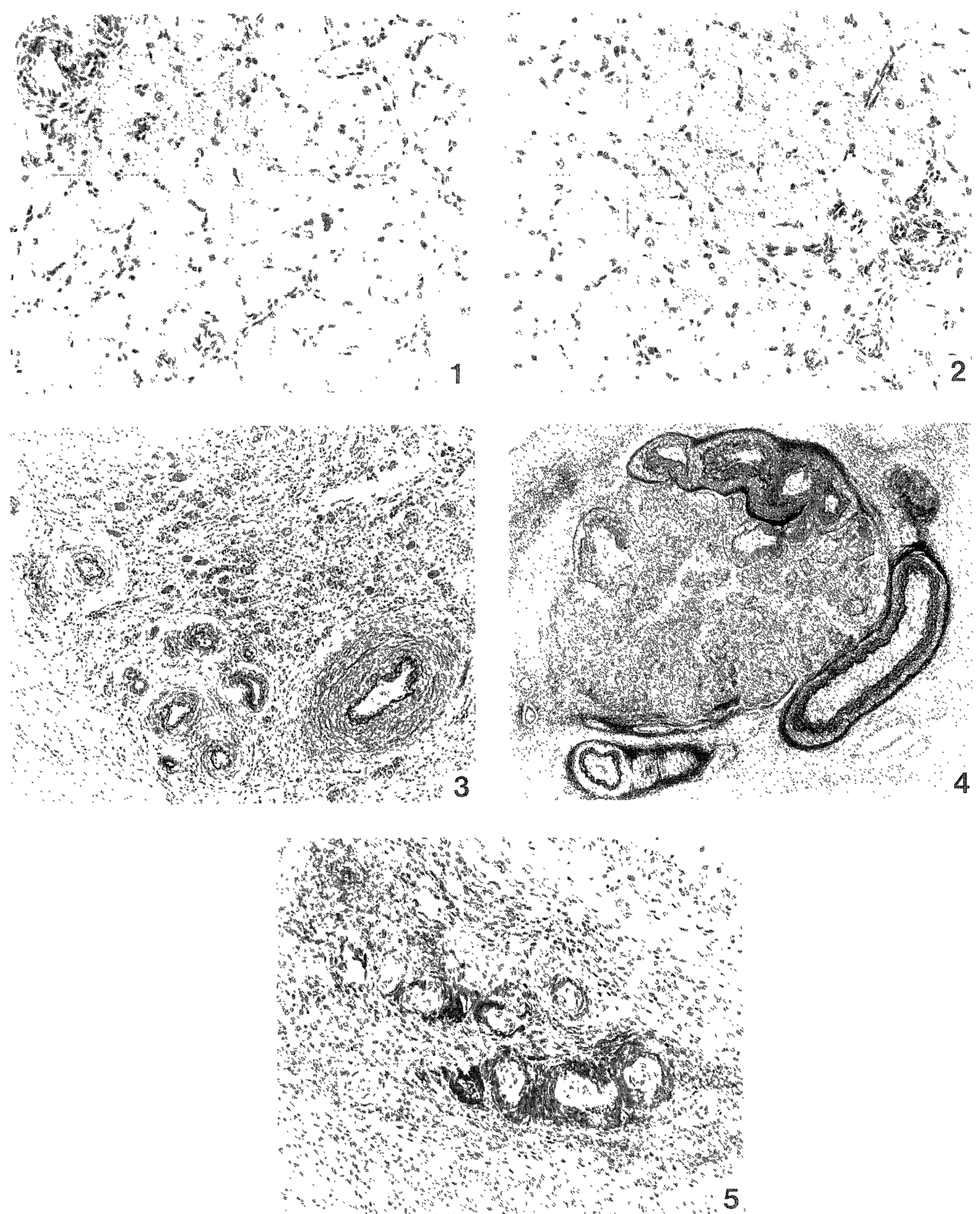

Fig. 1. Corpus luteum of pregnancy in the late period of gestation (fetus $3,600 \mathrm{~g}$ in weight). Degeneration of luteal cells is mild. $\times 150$, Hematoxylin-eosin stain (HE).

Fig. 2. ACL in the same ovary shown in Fig. 1. No histological differences from ACL are recognized. $\times 150$, HE.

Fig. 3. Corpus luteum of pregnancy soon after parturition. Many arteries and scattered degenerated luteal cells are seen. $\times 75$, Weigert's resorcin-fuchsin stain (W).

Fig. 4. RCL of pregnancy or RACL. Note an increase in the number of vessels and the proliferation of elastic fibers in the vessels' wall. $\times 30, \mathrm{~W}$.

Fig. 5. Old RCL of pregnancy or RACL. Advanced collapse of elastoid wall. $\times 150, \mathrm{~W}$. 
corpora lutea showed marked regressions; degeneration and disappearance of luteal cells were significant and the luteal size was reduced according as the cell number decreased. Moreover, the inflection of small arteries in the parenchyma resulted in increased number of vessels counted in histological sections and the proliferation of elastic fibers was observed in the capsular and parenchymal vessel wall (Fig. 3). At this stage, no more significant differences were observed in dimensions of the two different corpora lutea and the histological difference was almost impossible to detect.

$R C L$ of pregnancy and RACL: RCL of pregnancy and RACL were both irregular in shape with the diameter of less than $4 \mathrm{~mm}$ and had well developed arteries on their thick capsules and a number of small arteries in the parenchyma. These arteries showed the proliferation of elastic fibers, with older ones showing elastosis (Figs. 4, 5). Although luteal cells rarely remained in the parenchyma, the retrograded bodies could be easily identified on the basis of histological continuity from the corpora lutea seen immediately after deliveries.

By using the data from 46 age determined individuals, an analysis was made for the relationship between the total number of retrograded bodies (RCL of pregnancy + RACL) and the age; the number of retrograded bodies proved to increase with age (Fig. 6). If one female conceives one fetus yearly from the autumn at the age of 1.5 and two each corpora lutea are formed in every gestation, 2, 4, and $6 \mathrm{RCL}$ are to be cumulated in the ovaries at the age of $1.5,2.5$ and 3.5 , respectively, and so on. The actual numbers of retrograded bodies we observed were all distributed on or below the slanting straight line drawn by joining the cumulative numbers as above. Individually, one female of 10.5 years old and another of 12.5 years old had 12 and 11 retrograded bodies, respectively, while some others showed fewer values for their age, for example, 0 at 4.5-5.5 years old and 4 at 10.5 years old; an individual difference was generally considerable.

Corpora lutea of estrus: In the ovaries of two nonpregnant females captured in October ( 4 and 11 years old, the both multipara), corpora lutea were observed, which seemed to have been freshly formed soon after ovulation (Fig. 7). Granulosa layer and theca interna were curved to form wrinkles in the follicle cavity and had grown into a corpus luteum consisting of large polygonal and small spindle-shaped luteal cells. Furthermore, in the same two cases, in addition to those formed soon after ovulation, corpora lutea in the regressing process were also observed. In these corpora lutea, decrease in number of cells as well as cellular degeneration, with connective tissue increased were noted. Differing distinctly from regressing corpora lutea of pregnancy in that they were poor in developed blood vessels, they were considered to be corpora lutea of estrus formed at ovulation of one cycle before (Fig. 8).

RCL of estrus: In the ovaries of $2 / 6$ individuals captured in November were detected small hyaline bodies measur-

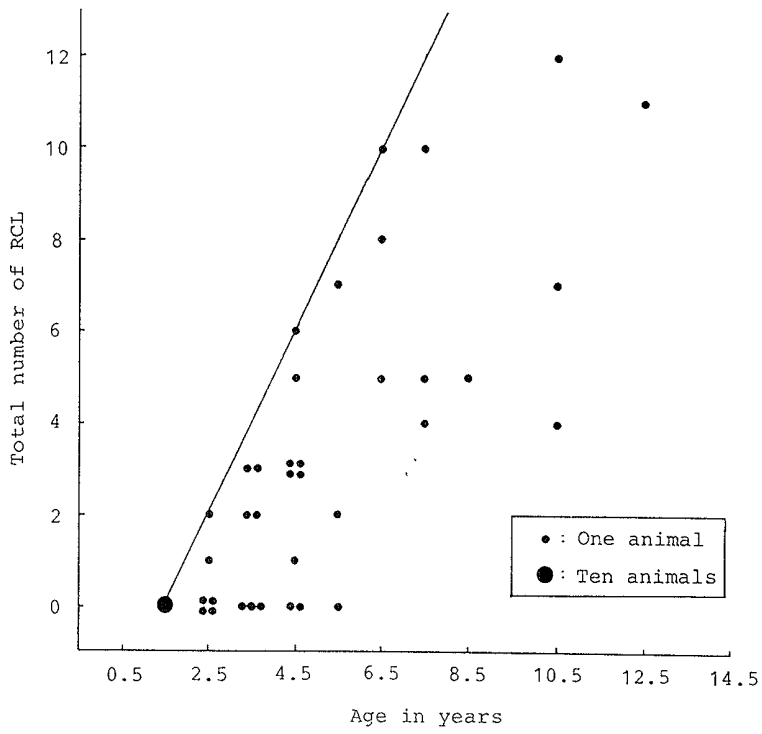

Fig. 6. Relationship between age and the total number of $\mathrm{RCL}$ of pregnancy and RACL. A slanting straight line shows expected numbers of RCL if one female conceives single fetus yearly from the autumn at the age of 1.5.

ing 2.5-3.8 $\mathrm{mm}$ in diameter and having no definite structure. Based on the fact that a small number of undegenerated or degenerated luteal cells were observed scattered in the hyaline matrix, they were assumed to be a type of the RCL's; in addition, since they were distinguishable easily from those of pregnancy in that the capsules and parenchyma were poor in a blood vessel, they were identified as RCL of estrus (Figs. 9, 10).

During February-March, 85 females were captured (45 pregnant, 40 not pregnant). Of these, two non-pregnant females had 5 and $6 \mathrm{RCL}$ of estrus in the ovaries, respectively (Figs. 11, 12). Except the two cases, all the females captured at this season had no RCL of estrus.

It is supposed that RCL of estrus progressively decrease in size and finally disappear by replacement with connective tissue, and that their structure at the final stage showed a close resembrance with atretic follicles (Fig. 13).

\section{DISCUSSION}

For deer of the subfamily Odocoilinae including the white-tailed deer and the black tailed deer, the examination of ovary has sometimes been used to evaluate their actual breeding conditions [3,5]. The two different RCL's, those of pregnancy and those of estrus were easily differentiated in that the formers were rich in blood vessels with solid wall, whereas the latter not $[7,10]$; in addition, it has been reported that the formers retained in the ovaries throughout the animal's life, while the latters disappeared within 6-18 months, leaving hyalinized scars [15].

In contrast to this, for deer of the subfamily Cervinae such as the red deer, the elk and the sika deer any method for the same end has not been completely established. As 

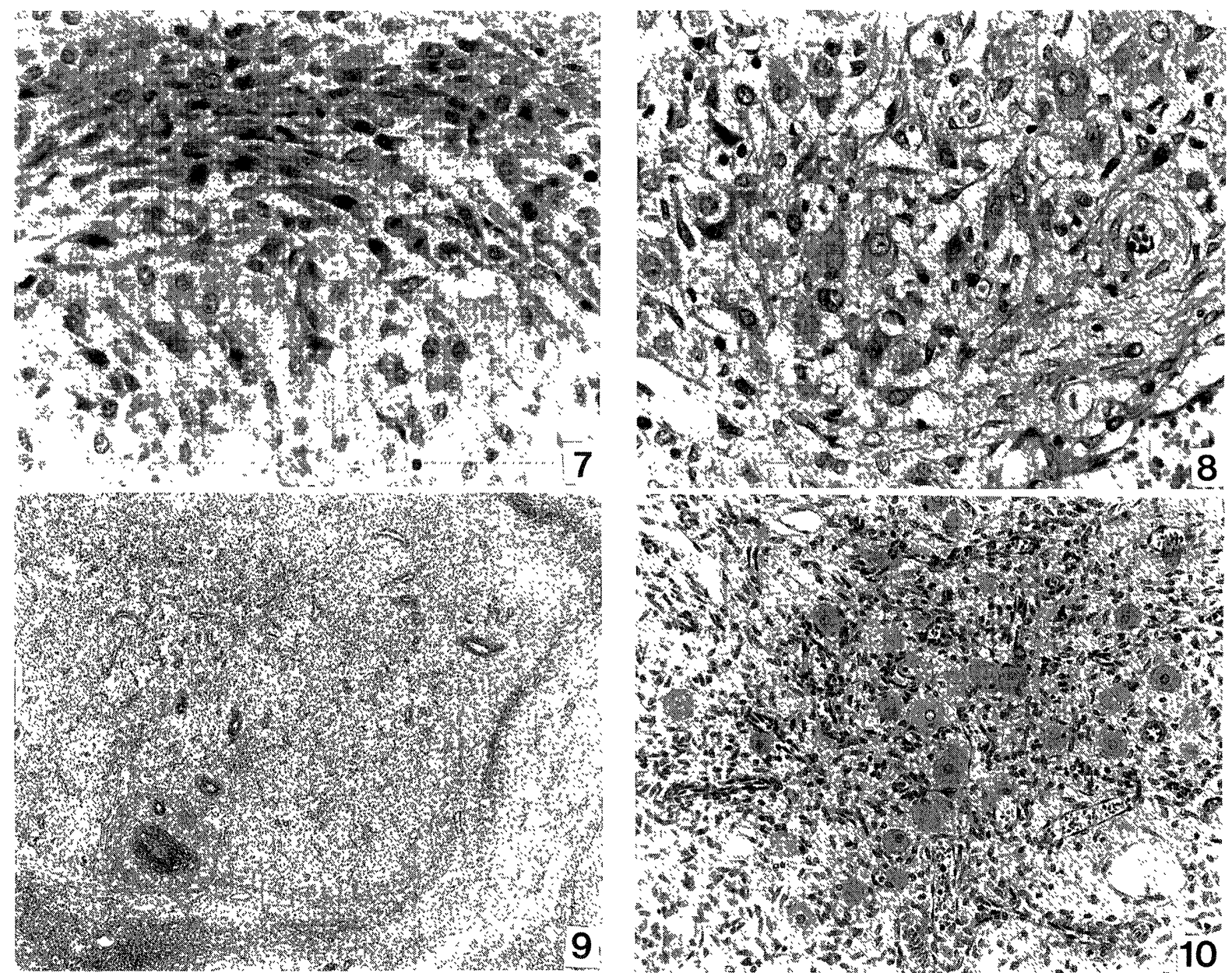

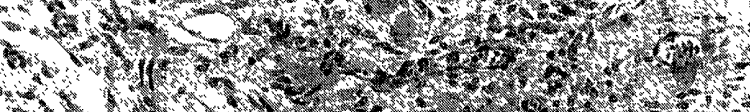

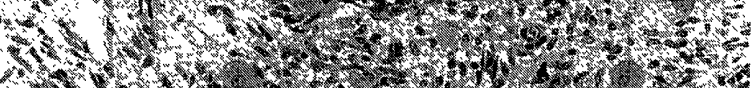
3. in a r.

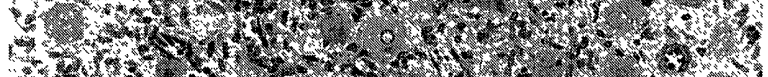
(1)

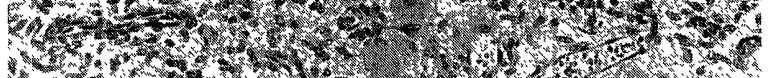
1.

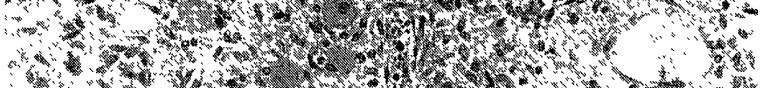

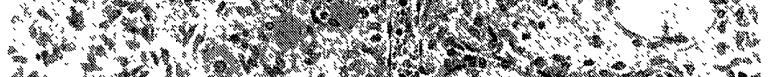
(2)
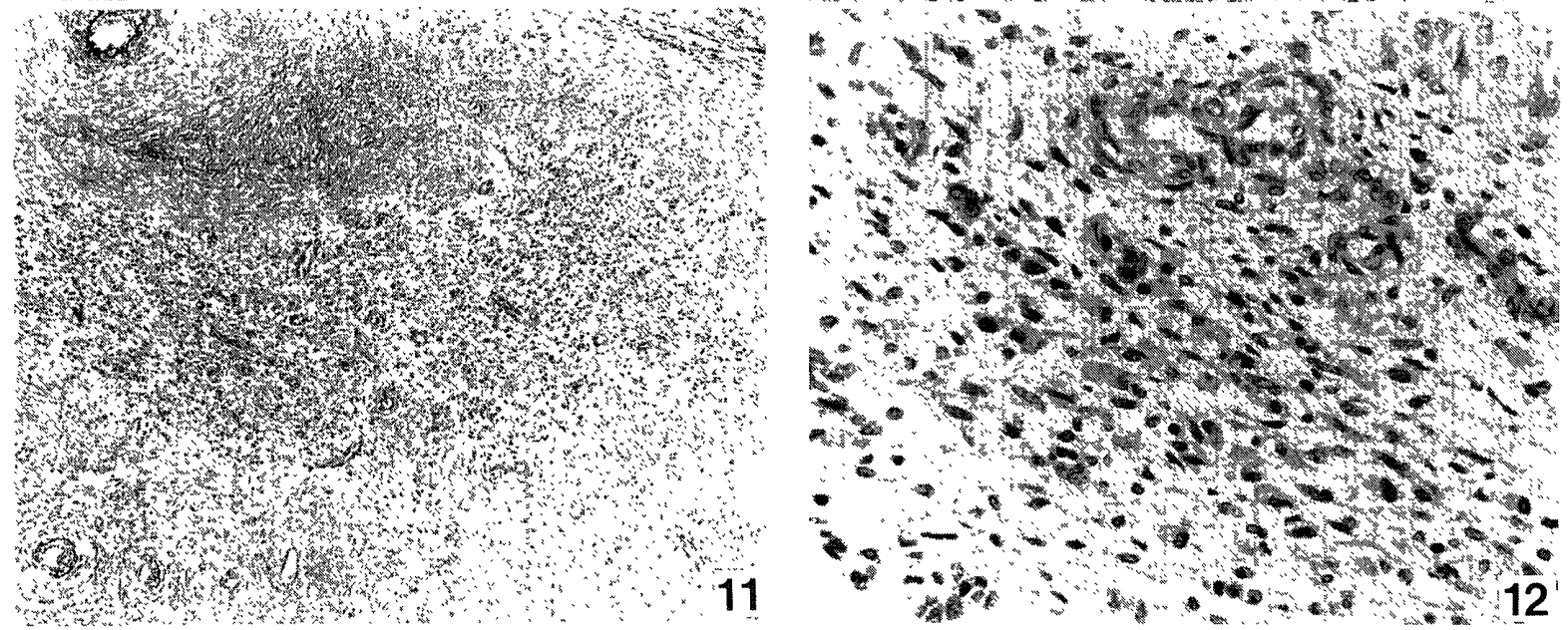

Fig. 7. Corpus luteum of estrus formed soon after ovulation. Large polygonal luteal cells (upper) and small spindle-shaped luteal cells (lower). $\times$ 300, HE.

Fig. 8. Regressing corpus luteum found in the same ovary shown in Fig. 7. Presumably, corpus luteum of estrus formed at ovulation of one cycle before. $\times 300, \mathrm{HE}$

Fig. 9. RCL of estrus found in the ovary of an animal captured in post-mating season (November). A few blood vessels are seen in the hyaline matrix. $\times 30, \mathrm{~W}$.

Fig. 10. Higher magnification of the upper-left part of Fig. 9. Degenerated and non-degenerated luteal cells are seen. $\times 150$, W.

Fig. 11. RCL of estrus found in the ovary of an animal captured in March. $\times 75, \mathrm{~W}$

Fig. 12. Higher magnification of the corpus showed in Fig. 11. A few degenerated luteal cells are seen. $\times 300$, HE. 


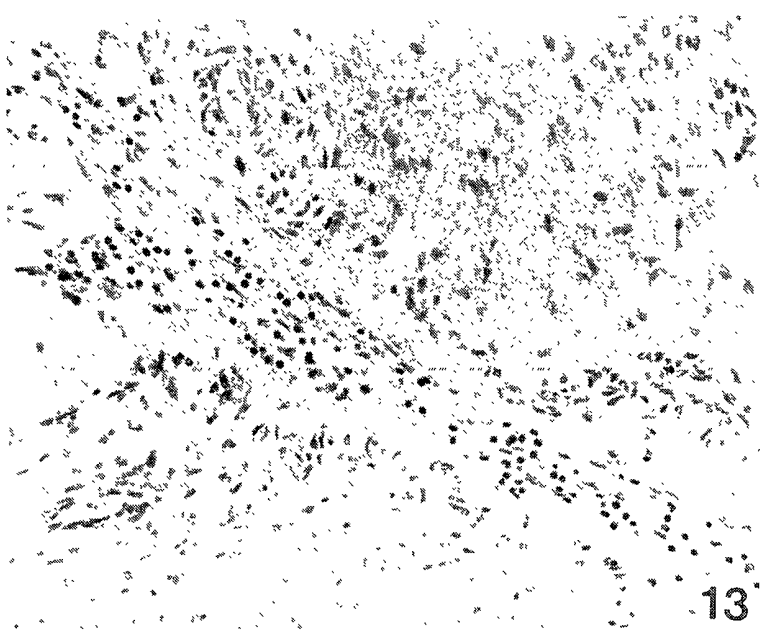

Fig. 13. An old RCL of estrus. $\times 150$, HE.

described above, so-called ACL are seen in pregnant females of these deer. These small bodies have been reported to appear in $79 \%, 66 \%$ and $81 \%$ of pregnant females of the red deer [4], elk [6] and sika deer [13], respectively. Their existence makes analysis of data on RCL difficult for the sika deer: although the existence of RCL of pregnancy can be used as an evidence of history of delivery, their numbers do not always indicate the actual number of delivery. Moreover, the term "accessory corpora lutea" has traditionally been used to mean luteinized follicles without ovulation [7] in the studies of Odocoilinae; such the confusion of terms among researchers of deer makes the problem more serious.

Concerning RCL of Cervinae deer species, Morrison [11] made an observation of corpora lutea of estrus in the retrograding process in the ovaries of elk and reported that masses of degenerated luteal cells were scattered in connective tissues, and that at 52 days after ovuation, the whole remained in the ovaries as white connective tissue. Concerning the sika deer, there was almost no report except Yamauchi et al. [16] who examined the ovaries of sika deer in Nara Park, the western part of Japan. According to them, one corpus luteum in the retrograding process was found in the ovaries of one female captured in June after delivery, two corpora lutea of estrus of different generations in one non-pregnant female captured in January and "corpora albicans (Corpora fibrosa)" in one one-year old female captured in February; but detailed description on their histological characteristics or differences were not given. That is, available data are so limited on RCL for the sika deer that the differences between the two types of retrograded bodies remain unclear.

Our findings on RCL of pregnancy in the sika deer were consistent well with those from the white-tailed deer [10]. In addition, the findings on RCL of estrus showed a good agreement with those from white-tailed deer [7] and the black-tailed deer [15]. The RCL of pregnancy were characterized by a number of well developed blood vessels in the capsule and the parenchyma and by increase in number or degeneration of elastic fibers in the blood vessels' wall, while RCL of estrus were lacking in such findings: these differences can be used to distinguish the two different retrograded bodies.

RCL of estrus appeared in materials examined during October and November but were rarely seen as fibrous scars in those examined during February and March, suggesting that they would disappear at a relatively early stage (probably within three months after formation). For the case of the two females which had RCL of estrus at our examination during February and March, it was supposed that the onset of ovulation had been considerably delayed than a usual mating season and several times of ovulation occurred thereafter.

The total number of RCL of pregnancy and RACL per female is in general greater than actual number of delivery: the relationship between the number and age suggests that both the retrograded bodies will retain in the ovaries over a long period. If the theoretically expected numbers of RCL, represented in a straight line in Fig. 6, are corrected by the average pregnancy rate in females over 2.5 years old at Mt. Goyo (90\%) [14] and the average frequency of occurrence of ACL in the previous reported sika deer $(81 \%)$ [13], the expected number in a 10.5-yearold female is 12 or 13 . In this study $12 \mathrm{RCL}$ were actually observed in a pair of ovaries of 10.5-year-old animal. The oldest of these RCL, therefore, is considered to be formed 7 or 8 years before. Hence, the lifetime of RCL of pregnancy and RACL may be estimated at more than 7 years. According to a demographic study at Mt. Goyo, pregnant ratio of one-year old and two-year old or more was $41.7 \%$ and $90.1 \%$, respectively, during the period from 1981 to 1988 , while they decreased to $20.0 \%$ and $78.9 \%$, respectively, in 1990 [14]. The total number of the retrograded bodies per female varied considerably, suggesting a great individual variation of reproductive ability. In the present study, there was a possibility that RACL were missed from examination at $2 \mathrm{~mm}$ intervals due to its smaller size than RCL of pregnancy. Therefore the thickness of sections should be improved so that all retrograded bodies can be detected.

ACKNOWLEDGEMENTS. The authors gratefully acknowledge very willing co-operation of the members of the Agricultural and Forestral Section of Ofunato City Office and those of the Nature Conservation Office of Iwate Prefecture. They also wish to thank students of Iwate University and Tohoku University as well as the members of local hunter's association for their assistance in sampling. Dr. T. Oi, Tohoku Research Center of Forestry and Forest Products Research Institute, contributed to age determination of the deer.

\section{REFERENCES}

1. Best, P. B. 1968. The sperm whale (Physeter catodon) off the west coast of south Africa. 2. Reproduction in the female. Div. Sea Fish. Invest. Rep. 66: 1-32.

2. Chapman, D. I. 1974. Reproductive physiology in relation to deer management. Mammal Rev. 4: 61-74.

3. Cheatum, E. L. 1949. The use of corpora lutea for determining ovulation incidence and variations in the 
fertility of white-tailed deer. Cornell Vet. 39: 282-291.

4. Douglas, M. J. W. 1966. Occurrence of accessory corpora lutea in red deer, Cervus elaphus. J. Mammal. 47: 152-153.

5. Golley, F. B. 1957. An appraisal of ovarian analyses in determining reproductive performance of black-tailed deer. J. Wildl. Manage. 21: 62-65.

6. Halazon, G. C. and Buechner, H. K. 1956. Postconception ovulation in elk. Trans. N. Am. Wildl. Natl. Res. Conf. 21: 545-554.

7. Harder, J. D. and Moorhead, D. L. 1980. Development of corpora lutea and plasma progesterone levels associated with the onset of the breeding season in white-tailed deer (Odocoileus virginianus). Biol. Reprod. 22: 185-191.

8. Kelly, R. W. and Challies, C. N. 1978. Incidence of ovulation before the onset of the rut and during pregnancy in red deer hinds. N. Z. J. Zool. 5: 817-819.

9. Kita, I., Sugimura, M., Suzuki, Y., Tiba, T., and Miura, S. 1987. Reproduction of female Japanese serow based on the morphology of ovaries and fetuses. pp. 321-331. In: The Biology and Management of Capricornis and Related Mountain Antelopes (Soma, H. ed.), Croom Helm, London.

10. Mansell, W. D. 1971. Accessory corpora lutea in ovaries of white-tailed deer. J. Wildl. Manage. 35: 369-374.

11. Morrison, J. A. 1960. Ovarian characteristics in elk of known breeding history. J. Wildl. Manage. 24: 297-307.

12. Sugimura, M., Kita, I., Suzuki, Y., Atoji, Y., and Tiba, T. 1984. Histological studies on two types of retrograde corpora lutea in the ovary of Japanese serows, Capricornis crispus. Zool. Anz. 213: 1-11.

13. Suzuki, M., Koizumi, T., and Kobayashi, M. 1992. Reproductive characteristics and occurrence of accessory corpora lutea in sika deer Cervus nippon centralis in Hyogo Prefecture, Japan. J. Mammal. Soc. Jpn. 17: 11-18.

14. Takatsuki, S. 1992. Report of Sika Deer of Mt. Goyo, Iwate Prefecture (in Japanese).

15. Thomas, D. C. and Cowan, I. McT. 1975. The pattern of reproduction in female Columbian black-tailed deer, Odocoileus hemionus columbianus. J. Reprod. Fertil. 44: 261-272.

16. Yamauchi, S., Murai, T., and Nishitani, Y. 1984. Studies on the ovary of the Japanese deer, Cervus nippon in the Nara Park - Postnatal development and seasonal changes Jpn. J. Anim. Reprod. 30: 162-173 (in Japanese with English summary). 